http://dx.doi.org/10.35381/racji.v6i10.1166

\title{
Asignación del carné de discapacidad y el delito de falsificación de documentos en el Ecuador
}

\section{Assignment of the disability card and the crime of falsification of documents in Ecuador}

\author{
José Rodolfo Alvarado-España \\ rodolfoalvarado125@hotmail.com \\ Universidad Regional Autónoma de los Andes, Quevedo \\ https://orcid.org/0000-0002-6192-6929 \\ César Elías Paucar-Paucar \\ uq.cesarpaucar@uniandes.edu.ec \\ Universidad Regional Autónoma de los Andes, Quevedo \\ Ecuador \\ https://orcid.org/0000-0003-2624-0427 \\ Alba Rosa Pupo-Kairuz \\ uq.albapupo@uniandes.edu.ec \\ Universidad Regional Autónoma de los Andes, Quevedo \\ https://orcid.org/0000-0002-1719-9250
}

Recepción: 10 de septiembre 2020

Revisado: 19 de octubre 2020

Aprobación: 18 de diciembre 2020

Publicación: 01 de enero 2021 


\section{Estimado Editor (a):}

En el Ecuador existe un marco jurídico favorecedor la protección de las personas con discapacidad, brindándole no solo apoyo para ser tratados en equidad de condición, aunado a la cooperación de crecimiento social - económico, a través de estrategias en instituciones públicas - privadas, como por ejemplo la adquisición de bienes de servicio y consumo con descuento, siendo necesario para tal fin, presentar un carnet de discapacitado, el cual es otorgado a través del Consejo Nacional para la Igualdad de Discapacidades (Centeno-Maldonado, et al., 2020).

Sin embargo, el Ecuador atraviesa una profunda crisis económica, política, moral, lo cual, propicia en personas habilidosas para los negocios al margen de la ley, el obtener un carnet sin ser discapacitado, esto con el afán de obtener los beneficios económicos propuestos exclusivamente a las personas con discapacidad y distinguidas con tal documento, incentivando así, a otro grupo de personas inescrupulosas (tramitadores), los cuales se dedican a negociar los carnés de discapacidad sin cumplir con todos los requerimientos y protocolos establecidos para la emisión de estos, conllevando a un incremento de la taza de emisión de carné de discapacidad (Zevallos, 2020).

En el Ministerio de Salud Pública del Ecuador, se ha provocado una alarma social por esta situación, estos funcionarios se aprovechan vilmente de las personas con discapacidad que son quienes realmente necesitan de la ayuda de estos beneficios, la gente ecuatoriana ya no puede seguir siendo indiferente ante lo que ha venido ocurriendo, no es el monto, no es el lugar donde ocurra (Tapia, 2020). Por lo tanto, se abre paso a la corrupción como mal destructor de la sociedad, aunado a ser un delito en contra del patrimonio público (Artaza-Varela, 2016), por consiguiente, en Ecuador se encuentra tipificado como delito la documentación falsa en el Artículo 328 del Código Orgánico Integral Penal de 2014, el cual se sanciona con pena privativa de libertad entre cinco a siete años. 
Por lo tanto, se debe investigar, procesar, a las personas que incurran en el delito de falsificación de carnés de discapacidad falsos, así como aquellos que, conociendo la procedencia dudosa del certificado, incurra en la adquisición de bienes y consumo con el descuento de ley previsto, por cuanto a su vez incurre en el delito de evasión de impuestos (De-La-Torre-Lascano, 2017).

En este sentido, la postura de los investigadores se justifica desde un orden social, jurídico, por cuanto se analiza la legalidad con la que se procede en el ejercicio de la asignación del carné de discapacidad, la importancia de la responsabilidad de emitirlos bajo los parámetros asignados por la ley el delito que cometen al falsificar documentos para poder obtener estos carnés, debido al impacto en los últimos tiempos por el alto índice de emisión de carnés de discapacidad que no cumplen todos los parámetros ni exigencias establecidos para portarlo siendo así estos carnés usados sin responsabilidad con dolo de beneficios personales y egoístas.

Por consiguiente, se hace un llamado a la ciudadanía a evitar estar prácticas fraudulentas que atentan contra el patrimonio público, así como a la ética colectiva, socavando la institucionalidad como pilar fundamental del Estado, haciéndose un llamado a quienes dirigen los organismos encargados de ejecutar la justicia, así como a los legisladores, a trabajar en común para el fortalecimiento del orden jurídico en el Ecuador, con lo cual, gana la sociedad en razón de transitar hacia el bienestar público como precepto de convivencia del buen vivir.

\section{FINANCIAMIENTO}

No monetario.

\section{AGRADECIMIENTO}

A la Universidad Regional Autónoma de los Andes, Quevedo; por motivar el desarrollo de la Investigación. 


\section{REFERENCIAS CONSULTADAS}

Artaza-Varela, O. (2016). La utilidad del concepto de corrupción de cara a la delimitación de la conducta típica en el delito de cohecho [The usefulness of the concept of corruption regarding the delimitation of the typical behavior in the crime of bribery]. Política criminal, 11(21), 307-339. https://dx.doi.org/10.4067/S0718$\underline{33992016000100011}$

Centeno-Maldonado, P., Haro-Altamirano, A., \& Peralta-Vargas, S. (2020). Distribución de los carnets de discapacidad desde el ámbito administrativo en tiempos de pandemia [Distribution of disability cards from the administrative field in times of pandemic]. IUSTITIA SOCIALIS, 5(3), 196-206. http://dx.doi.org/10.35381/racji.v5i3.1095

Código Orgánico Integral Penal. Registro Oficial № 180. Lunes 10 de febrero de 2014. https://n9.cl/g6sc

De-La-Torre-Lascano, C. (2017). Relación existente entre paraísos fiscales, lavado de activos y defraudación tributaria. Un análisis desde la normativa de Ecuador [Existing relationship between tax havens, money laundering and tax defraud. An analysis from the norms of Ecuador]. Revista de la Facultad de Derecho, (43), 331. https://dx.doi.org/10.22187/rfd2017n2a2

Tapia, L. (2020). 22 funcionarios son investigados por entrega fraudulenta de carné de discapacidad. [22 officials are investigated for fraudulent delivery of disability cards]. Recuperado de https://n9.cl/iifi

Zevallos, J. C. (2020). 3000 carnés de discapacidad se emitieron de 'manera ilegal', durante la pandemia del covid-19. [3000 disability cards were issued 'illegally', during the covid-19 pandemic]. Recuperado de https://n9.cl/loyp4

(C2021 por los autores. Este artículo es de acceso abierto y distribuido según los términos y condiciones de la licencia Creative Commons Atribución-NoComercial-Compartirlgual 4.0 Internacional (CC BY-NC-SA 4.0) (https://creativecommons.org/licenses/by-nc-sa/4.0/). 